Article

\title{
Consumption of Hydrocarbons and Its Relationship with Ozone Formation in Two Chinese Megacities
}

\author{
Chih-Chung Chang ${ }^{1}$, Hwa-Kwang Yak ${ }^{2}$ and Jia-Lin Wang ${ }^{3, *}$ \\ 1 Research Center for Environmental Changes, Academia Sinica, Taipei 11529, Taiwan; \\ joechang@gate.sinica.edu.tw \\ 2 Department of Chemistry, Chung Yuan Christian University, Taoyuan 32023, Taiwan; hkyak@cycu.edu.tw \\ 3 Department of Chemistry, National Central University, Chungli 320, Taiwan \\ * Correspondence: cwang@cc.ncu.edu.tw; Tel.: +886-3-4227734; Fax: +886-3-4277972
}

Received: 21 February 2020; Accepted: 24 March 2020; Published: 27 March 2020

check for updates

\begin{abstract}
Continuous measurements of ozone and its precursors were performed at sites in two Chinese megacities, i.e., an urban site in Beijing and a suburban site in the Pearl River Delta (PRD). At both sites, the total oxidants $\left(\mathrm{O}_{3}+\mathrm{NO}_{2}\right)$ varied with the ratio of ethylbenzene to $\mathrm{m}$, $\mathrm{p}$-xylenes, which serves as an indicator of photochemical aging. An observation-based method (OBM) was derived for calculating the photochemical consumption of individual non-methane hydrocarbons (NMHCs) based on the observed NMHC concentrations and the ratio of ethylbenzene to m,p-xylenes. The results show a strong correlation between the oxidant level and the derived consumption of precursors at the two sites $\left(R^{2}=0.81\right.$ for the PRD site and $R^{2}=0.83$ for the Beijing site), demonstrating a strong cause-effect relationship. The relative "consumption efficiency" among NMHCs was calculated based on the integrated amount of hydroxyl radicals derived from the ratio of ethylbenzene to xylenes. Thus, the percent contributions to ozone formation from each individual NMHC can be calculated. This concept of consumption is purely observation-based and provides an easy way to bypass complicated modeling and the necessity of knowing instantaneous concentrations of hydroxyl radicals, which are highly illusive in nature.
\end{abstract}

Keywords: aging indicator; non-methane hydrocarbons (NMHCs); consumption efficiency

\section{Introduction}

Beijing, the capital of China, is a major urban center located on the North China Plain. Over the last few decades, rapid economic growth and an increased number of vehicles in Beijing increased its atmospheric pollution. High ozone levels and fine particulate matter $\left(\mathrm{PM}_{2.5}\right)$ were common over the 1998-2015 period in the Beijing area [1-4]. Following strict pollution control measures introduced in 2013, PM2.5 levels dropped significantly, but ozone pollution did not improve [4,5]. The ozone levels in Beijing frequently exceeded the national daily ozone standard $\left(0.20 \mathrm{mg} / \mathrm{m}^{3}\right.$, approximately $\left.100 \mathrm{ppb}\right)$, with more occurrences in the summer than in other seasons [6]. In the south, the Pearl River Delta (PRD), adjacent to Hong Kong on the southern coast of China, has been China's most populated and rapidly developing region since the early 1980s. The rapid economic growth was accompanied by worsening air quality, with ozone being one of the most important pollutants $[4,7,8]$. It is well known that ozone in the lower troposphere is directly linked to its precursors-volatile organic compounds (VOCs) and $\mathrm{NO}_{X}$ (e.g., [9-11]). Most investigations of the relationship between ozone and its precursors are based on models that rely on inputs of precursor emission rates, chemical reactions and atmospheric dynamics. Model simulation is widely accepted as a useful means for diagnosing ozone-VOC-NOX chemistry. However, model-based predictions of ozone concentrations are dependent on assumptions 
and approximations of chemical kinetics and transport and precursor emission rates. Model results can vary significantly given different assumptions and uncertain emission inventories.

Several observation-based methods (OBMs) were developed to assess the relationship between ozone and its precursors directly from field observations (e.g., VOCs, reactive nitrogen and peroxides), bypassing the reliance on model assumptions. The results obtained from OBMs can be used to study region-specific ozone-formation processes and tailor effective ozone-control strategies [12-16]. To develop effective OBMs, the amounts of precursors consumed by photochemistry during ozone formation, also known as precursor consumption, must be known and quantified beforehand.

In the present study, we estimate the precursor consumption by measuring ambient non-methane hydrocarbons (NMHCs) and the ratio of ethylbenzene to $\mathrm{m}, \mathrm{p}$-xylenes as an indicator of photochemical removal or aging. The method considers the "cumulative consumption" of precursor NMHCs in a moving air parcel and uses it to evaluate the relationship between ambient ozone levels and photochemically consumed NMHCs. The concept of consumption is similar to the one used in correlations of $\mathrm{NO}_{Z}$ with ozone $[17,18] . \mathrm{O}_{3}-\mathrm{NO}_{Z}$ correlations were used to assess $\mathrm{NO}_{X}$-sensitive chemistry and to estimate ozone production efficiency (ozone molecules produced per $\mathrm{NO}_{X}$ of molecule consumed), where $\mathrm{NO}_{Z}$ represents the sum of species produced by the removal of $\mathrm{NO}_{X}$. In this study, the consumption of NMHCs was estimated based on the kinetics of reactions of individual NMHCs with the hydroxyl radicals $(\mathrm{OH})$. Consumption was assessed for each individual NMHC and the method was subsequently extended to calculate the consumption of carbon monoxide (CO).

\section{Methodology}

\subsection{Site Description and Instrumentation}

Two corporative measurement campaigns were conducted in PRD and Beijing in 2006. The PRD campaign (Program of Regional Integrated Experiments of Air Quality over the Pearl River Delta, PRIDE-PRD2006) took place from 3 July 2006 to 31 July 2006 [19]. An onsite continuous measurement of ozone and its precursors was performed at Backgarden (BG), a regional background site approximately $60 \mathrm{~km}$ northwest of Guangzhou, which is surrounded by agriculture farmlands. During the campaign, the temperature was $28-36{ }^{\circ} \mathrm{C}$ and the relative humidity was $60 \%-90 \%$, typical for a subtropical region during the rainy season. The wind speed was generally $<2 \mathrm{~m} / \mathrm{s}$ and the wind direction was usually southerly. Thus, BG was expected to be in the downwind region of the PRD during this period. The instruments were installed on the roof of a three-story building ( $10 \mathrm{~m}$ above ground). An automated gas chromatograph (GC) with flame ionization detection (FID) was deployed to make hourly measurements of 51 target NMHCs in the range $C_{3}-C_{12}$. Detailed descriptions of the analytical method, the target species and the quality control procedure can be found in Wang et al. [20]. In addition, $\mathrm{NO}_{\mathrm{X}}, \mathrm{O}_{3}$ and $\mathrm{CO}$ were measured onsite simultaneously [21]. In brief, $\mathrm{NO}_{2}$ was measured via photolytic conversion into NO (Droplet Measurement Technologies, Model BLC), followed by $\mathrm{NO}-\mathrm{O}_{3}$ chemiluminescence detection (Model 42C-TL, Thermo Electron Co.). Ozone was measured using an ultraviolet (UV) absorption instrument (Model 49C, Thermo Electron Co.), while CO was measured by a non-dispersive infrared (NDIR) gas analyzer (Model 48C, Thermo Electron Co.). Details of the analytical methods and quality assurance can be found in Lou et al. [19]. Continuous measurements of ozone and its precursors were averaged into more than 500 hourly data points.

The second campaign took place from 15 August 2006 to 10 September 2006 and was designed to investigate the chemical conditions that produce the air quality conditions typical of Beijing (CAREBEIJING-2006). The same types of instruments as in the previous campaign were used to provide continuous measurements of ozone and its precursors [20,22]. The instruments were deployed on the campus of Peking University (PKU campus) in the northwest of downtown Beijing; an area that is surrounded by major traffic arteries and residential areas. The air inlet was set up on the roof of a six-story building ( $20 \mathrm{~m}$ above ground). The weather was hot and humid with a mild southerly breeze during the campaign period. Over 600 hourly average data points were collected. 


\subsection{Method of Estimating Consumption of Precursor NMHCs}

The OBM used to estimate the precursor consumption was derived from a study by Lee et al. [23], in which an innovative concept was raised in that the observed mixing ratio of a given NMHC should be deemed a residue left over from photochemical reactions.

The amounts of consumed NMHCs were estimated by subtracting the observed ambient concentrations (residue) from their derived initial concentrations. The details and validation of the method were described in an earlier publication [24]. In this study, the ratio of ethylbenzene to $\mathrm{m}$,p-xylenes (m-xylene plus p-xylene) was used as an indicator of photochemical aging to estimate the degree of photochemical removal. Ethylbenzene and $\mathrm{m}, \mathrm{p}$-xylenes primarily originate from common anthropogenic sources and have a nearly constant emission ratio [25]. Because separating $\mathrm{m}$ - and p-xylene by gas chromatography (GC) without compromising the overall separation of most major NMHCs is technically difficult, the combined signal was used, yielding a weighted average rate constant of $20.5 \times 10^{-12} \mathrm{~cm}^{3} \cdot \mathrm{s}^{-1}$ for the joint $\mathrm{m}$, $\mathrm{p}$-xylenes by taking their separate rate constants with $\mathrm{OH}$ of $23.1 \times 10^{-12} \mathrm{~cm}^{3} \cdot \mathrm{s}^{-1}$ for $\mathrm{m}$-xylene and $14.3 \times 10^{-12} \mathrm{~cm}^{3} \cdot \mathrm{s}^{-1}$ for $\mathrm{p}$-xylene [26]. The $\mathrm{m}$-xylene/p-xylene ratio was found to be $2.33 \pm 0.30$, based on 706 samples [25].

The rate constant for $\mathrm{m}, \mathrm{p}$-xylenes is larger than that for ethylbenzene by a factor of 3 , leading to faster removal of $\mathrm{m}, \mathrm{p}$-xylenes than ethylbenzene in ambient air $[27,28]$. Assuming an air parcel follows a Lagrangian trajectory, the difference in removal rates causes the ethylbenzene/m,p-xylenes $(\mathrm{E} / \mathrm{X})$ ratio of the air parcel to increase as photochemistry progresses [27], as indicated by the following kinetic equation:

$$
\left.(E / X)_{t}=(E / X)_{0} \exp \left(-\left(k_{e}-k_{x}\right) \int_{0}^{t}[O H] d t\right)\right)
$$

where $(E / X)_{t}$ represents the concentration ratio of ethylbenzene to $\mathrm{m}, \mathrm{p}$-xylenes at time $\mathrm{t}$ and $(E / X)_{0}$ is the initial concentration ratio of ethylbenzene to $\mathrm{m}, \mathrm{p}$-xylenes in the early morning $(t=0)$ before significant photochemistry takes place. As given above, the rate constants for ethylbenzene $\left(k_{e}\right)$ and $\mathrm{m}$,p-xylenes $\left(k_{x}\right)$ were $7.0 \times 10^{-12} \mathrm{~cm}^{3} \cdot \mathrm{s}^{-1}$ and $20.5 \times 10^{-12} \mathrm{~cm}^{3} \cdot \mathrm{s}^{-1}$, respectively [26]. The initial value $(E / X)_{0}$ was around $0.69 \pm 0.12$ (mean \pm standard deviation) for BG (PRD) and $0.58 \pm 0.08$ for PKU (Beijing). Note that $(E / X)_{0}$ may be different in different cities or regions, but it is generally fixed in a given area $[25,29]$. Using the measured values of $(E / X)_{t}$ and $(E / X)_{0}$, the degree of photochemical processing, denoted $\int_{0}^{t}[O H] d t$, can be obtained from Equation (1).

We used the observed individual NMHC concentrations at time $t$ and the derived degree of photochemical processing $\left(\int_{0}^{t}[\mathrm{OH}] d t\right)$ to obtain the initial concentrations of individual NMHCs $(\mathrm{t}=0)$. These were calculated using Equation (3), which is derived from the simplified Equation (2), assuming that air parcels follow Lagrangian trajectories with only NMHC loss from a pseudo-first-order reaction with $\mathrm{OH}$ :

$$
\begin{gathered}
d[\mathrm{NMHC}] / d t=-k_{i}[\mathrm{NMHC}][\mathrm{OH}] \\
{[\mathrm{NMHC}]_{t}=[\mathrm{NMHC}]_{0} \exp \left(-k_{i} \int_{0}^{t}[\mathrm{OH}] d t\right)}
\end{gathered}
$$

where $k_{i}$ is the rate constant for the reaction of each individual NMHC with $\mathrm{OH}$ [26] and [NMHC] $]_{t}$ and $[\mathrm{NMHCs}]_{0}$ represent the concentrations of a given NMHC at times $t$ and zero, respectively. The observed NMHC concentration at time $t$ and $\int_{0}^{t}[\mathrm{OH}] d t$ derived from Equation (1) were used in Equation (3) to obtain the initial NMHC concentration $(t=0)$. Subsequently, the consumption of each individual NMHC between early morning $(t=0)$ and time $t$ was calculated by subtracting the observed NMHC concentration at time $t$ (the quantity remaining after photochemical reaction) from the initial NMHC concentration. In our calculation, we took into account the chain length of each NMHC and its 
stepwise degradation (with each step likely leading to oxidant formation) by multiplying the carbon number of an NMHC by the amount consumed with a unit ppbC.

The amount of $\mathrm{CO}$ consumed by $\mathrm{OH}$ was also derived using this method. Although $\mathrm{CO}$ is not as reactive as NMHCs, it is highly abundant in urban environments, potentially contributing a non-negligible amount of oxidant [30,31].

Isoprene was treated separately from anthropogenic VOCs due to its extremely high photochemical reactivity and very different source nature from other observed NMHCs [23,32-35]. The two field campaigns were carried out in the summer, when isoprene emissions thrived, peaking at noon and falling rapidly at night. The isoprene mixing ratios observed at both sites were mostly overwhelmed by the nearby vegetation source. Because of its dramatic diurnal feature, we took half of the observed isoprene to represent the steady-state concentration. The consumption of isoprene is estimated slightly differently than other species, which is assumed to be proportional to both the steady-state concentrations of isoprene and ambient $\mathrm{OH}$, as well as the reaction time $\mathrm{t}$ :

$$
\text { Consumption of isoprene }(\text { from time } 0 \text { to } \mathrm{t})=-\mathrm{k}_{\text {isoprene }} \times[\text { isoprene }]_{\mathrm{t}} / 2 \times \int_{0}^{t}[\mathrm{OH}] d t
$$

where [isoprene $]_{t} / 2$ represents the average concentration of isoprene from early morning $(t=0)$ to time $\mathrm{t}$ (the build-up phase).

To evaluate the atmospheric relationship between ozone production and NMHC (and CO) consumption in the atmosphere, we used total oxidants $\left(\mathrm{O}_{3}+\mathrm{NO}_{2}\right)$ instead of ozone alone. $\mathrm{O}_{3}$ and $\mathrm{NO}$ are rapidly interchanged via NO titration in an intense photochemical condition [36-39]; thus, using only ozone concentrations leads to underestimates of photochemically produced ozone. Using total oxidant instead provides more accurate estimates of ozone formation during a photochemical process.

\section{Results and Discussion}

\subsection{Relationship between Consumed NMHCs and Total Oxidant}

The time series of oxidant $\left(\mathrm{O}_{3}+\mathrm{NO}_{2}\right)$ concentrations and $\mathrm{E} / \mathrm{X}$ ratios at both sites are shown in Figure 1, which illustrates the diurnal variation of photochemical processing. At both sites, the oxidant concentration and the $\mathrm{E} / \mathrm{X}$ ratio vary simultaneously, suggesting that their relationship is tightly coupled. Note that the coherence of the two was clear and apparent, since the measurements were continuous, which may not be easily observed if conducted by random sampling. The daily maximum $\mathrm{E} / \mathrm{X}$ ratio occurred in the early afternoon (1 p.m. to 3 p.m. at BG and 12 p.m. to 2 p.m. at PKU), coinciding with the oxidant peak. Figure $2 \mathrm{a}$, b shows the correlation between daily maximum oxidant concentrations and their corresponding $E / X$ ratios at BG $\left(R^{2}=0.53\right)$ and PKU $\left(R^{2}=0.68\right)$. The positive correlation suggests a close relationship between the two observed variables, which underscores the potential usefulness of $\mathrm{E} / \mathrm{X}$ as an indicator of photochemical processing. At $\mathrm{BG}$, a typical suburban site on the outskirts of Guangzhou, both the maximum E/X and oxidant values occurred around 3 p.m., about an hour later than at PKU (2 p.m.). We speculate that the 1-hour difference was caused by a longer transport time to BG than to PKU due to the greater distance from the source region to the measurement site at BG.

Oxidant and NMHC concentrations are usually uncorrelated, because the observed NMHCs at a given time have not participated in the prior oxidant formation; thus, they do not contribute to the preexisting oxidant levels. Shown in Figure $2 c, d$, the scatter plots of oxidant $\left(\mathrm{O}_{3}+\mathrm{NO}_{2}\right)$ versus observed total NMHC concentrations during the periods with daily maximum oxidants revealed that they were nearly uncorrelated. Interestingly, after the amounts of consumed NMHCs and CO are calculated, a much-improved correlation appears between the observed oxidant level and the total consumed NMHCs + CO, with $\mathrm{R}^{2}=0.81$ for BG and $\mathrm{R}^{2}=0.83$ for PKU. (Figure 2e,f). The improved correlation can be explained as follows: the more NMHCs and CO are consumed, the higher the oxidant 
level that can be expected. The result also indicates that the oxidant level is linked to the degree of photochemical processing and the precursors' level. Observational and modeling results suggest that ozone formation in urban areas is a VOC-limited chemical regime, whereas ozone formation in rural regions is $\mathrm{NO}_{\mathrm{X}}$-limited $[4,11,40]$. The excellent correlations between NMHC consumption and oxidant $\left(\mathrm{O}_{3}+\mathrm{NO}_{2}\right)$ indicate that the relative $\mathrm{NO}_{\mathrm{X}}$ levels are either high or constant and that ozone formation in these two Chinese cities is VOC-limited and not $\mathrm{NO}_{\mathrm{X}}$-limited. This concept of consumption is purely observation-based. It provides an easy way to bypass complicated modeling. Other parameters that are required for modeling, such as meteorology and $\mathrm{OH}$ concentration, are implicitly included in $\int_{0}^{t}[O H] d t$, which is determined from the observed values of $(E / X)_{0}$ and $(E / X)_{t}$.
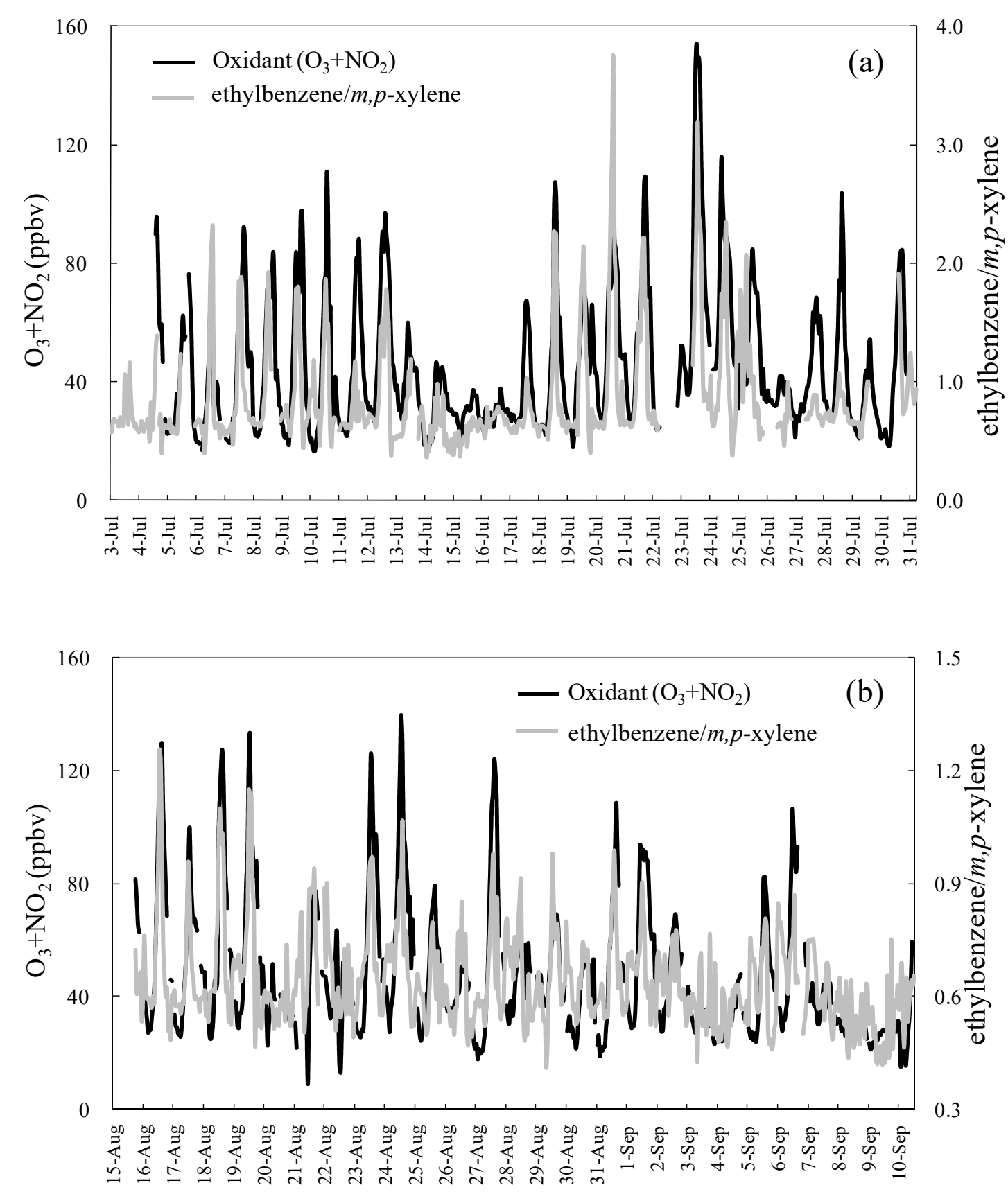

Figure 1. Time-series of oxidant $\left(\mathrm{O}_{3}+\mathrm{NO}_{2}\right)$ observations and $\mathrm{E} / \mathrm{X}$ ratios at (a) Backgarden (BG), PRD and (b) PKU, Beijing. 

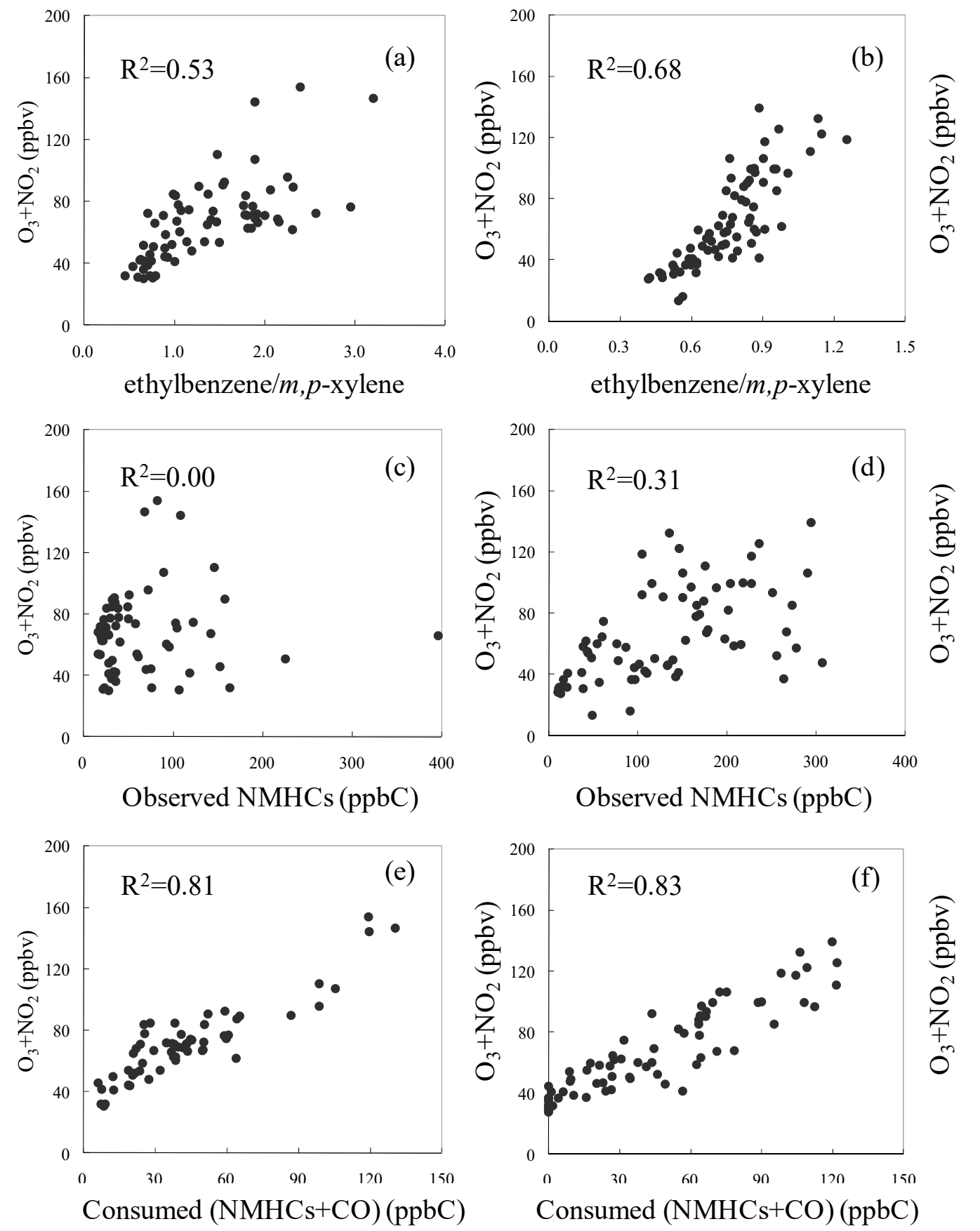

Figure 2. Scatter plots of oxidant $\left(\mathrm{O}_{3}+\mathrm{NO}_{2}\right)$ versus ethylbenzene/m,p-xylenes ratio, observed total NMHC concentrations, and total consumed NMHCs+CO at BG, PRD (a,c,e) and PKU, Beijing (b,d,f). Data were selected from 13:00 to 15:00 at BG and 12:00 to 14:00 at PKU. (ppbC: parts per billion carbon, ppbv: parts per billion by volume).

\subsection{Uncertainties in the Relationship between Oxidant and Precursors}

Uncertainties in this method can affect the overall quality of the relationship seen in Figure 2e,f. Other than the two possible sources of error that could affect the accuracy of aging and consumption calculation, i.e., the injection of fresh emissions and pre-existing ozone [24], another source of uncertainty is the missing $\mathrm{C}_{2}$ NMHCs not measured by the online GC. The online GC used at both stations measured $\mathrm{C}_{3}-\mathrm{C}_{12}$ NMHCs [41] but no $\mathrm{C}_{2}$ species (ethane, ethene and ethyne), due to instrumental limitations. Ignoring these species can result in an underestimation of the total NMHC consumption. Our earlier findings at both BG and PKU showed that ethane, ethene and ethyne together accounted for about $15 \%$ 
of the total $C_{2}-C_{11}$ NMHC carbon-number-adjusted abundance [41,42]. However, due to their relatively low reactivity, $C_{2}$ species only accounted for approximately $5 \%$ of the total NMHC consumption at both BG and PKU (calculated using the method proposed in this study). Even though the consumption of most alkenes happens mainly through their reaction with $\mathrm{OH}$, some alkenes can react with ozone and $\mathrm{NO}_{3}$, especially during daytime [43]. The consumption of alkenes by ozone and $\mathrm{NO}_{3}$ can cause underestimates of the alkenes' consumption. Even so, it does not change the fact that alkenes are important parts of the total consumption due to the relatively larger contribution from $\mathrm{OH}$ than from ozone and $\mathrm{NO}_{3}$. Although sources of uncertainty like these generally decrease the correlation between observed oxidant level and estimated precursor consumption, the high correlations seen in Figure 2e, $\mathrm{f}$ demonstrate that these factors are not significant and do not seriously obscure the photochemical relationship between the oxidant and its precursors.

\subsection{Absolute Abundance versus Consumed NMHCs and CO}

As previously discussed, for an air parcel advected to the observation site with minimal mixing, the observed NMHC concentrations represent the remaining NMHCs, i.e., unreacted NMHCs. Section 2.2 describes an OBM used to calculate NMHC consumption, reflecting NMHC reactivity with $\mathrm{OH}$ integrated over a period determined by both $(E / X)_{0}$ and $(E / X)_{t}$. Figure 3 shows consumption of individual NMHCs at BG and PKU during the periods of daily maximum oxidant occurrence. Note that CO consumption was surprisingly large as compared to that of NMHCs, accounting for over $15 \%$ of the total consumption at BG and $12 \%$ at PKU. It was the extremely high abundance of CO (the red bar in Figure $3 \times 1000=$ true mixing ratio in ppbv) that contributes to the substantial consumption despite its month-long atmospheric lifetime. Note that the isoprene's percent consumption was significant (about $17 \%$ at BG and $9 \%$ at PKU) due to its extremely high reactivity. Higher isoprene concentrations were observed at BG than at PKU because of the suburban-rural nature of the BG site where vegetation is substantially more abundant. Propene was another major contributor at $B G$, following only isoprene and $\mathrm{CO}$ in the ranking and accounting for $13 \%$ of the consumption at $\mathrm{BG}$, compared to about $3 \%$ at PKU. The higher propene and propane levels at BG were likely driven by incomplete combustion of liquefied petroleum gas (LPG) used as vehicle fuel in the PRD [41]. Although the observed alkene levels were much lower than levels of alkanes and aromatics at both sites, the overall higher reactivities of alkenes accentuated their role, leading to their large contributions to total consumption.

To measure the efficiency with which a given precursor is consumed, the "consumption efficiency" is determined by calculating the ratio of the consumed amount of each species ([NMHC $]_{0}-[\mathrm{NMHC}]_{\mathrm{t}}$ ) to the initial amount ([NMHC $]_{0}$ ), as shown in Equation (5), which is derived from Equation (3):

$$
\text { Consumption efficiency }=1-\exp \left(-k_{i} \int_{0}^{t}[\mathrm{OH}] d t\right)
$$

This value is a function of the rate constant of reaction with $\mathrm{OH}$ and the degree of aging $\left(\int_{0}^{t}[\mathrm{OH}] d t\right)$; thus, it is compound-dependent and can be compared across species. The higher the consumption efficiency, the more oxidant can be formed from an NMHC species during a photochemical process. Of the three groups of NMHCs, alkanes had the lowest average efficiency ( 0.25 at BG and 0.14 at $\mathrm{PKU})$; hence, they were the least effective in producing oxidant. In contrast, alkenes had the highest average efficiency ( 0.74 at $B G$ and 0.62 at PKU) and were, thus, the most efficient in producing oxidants. Aromatic efficiency was intermediate: 0.44 at BG and 0.30 at PKU. The efficiencies at BG were generally higher than those at PKU because of the greater degree of aging at BG, as evidenced by the larger $\int_{0}^{t}[\mathrm{OH}] d t$ value. Although the consumption of $\mathrm{CO}$ was large, the $\mathrm{CO}$ consumption efficiency was only about 0.01 at both BG and PKU. 

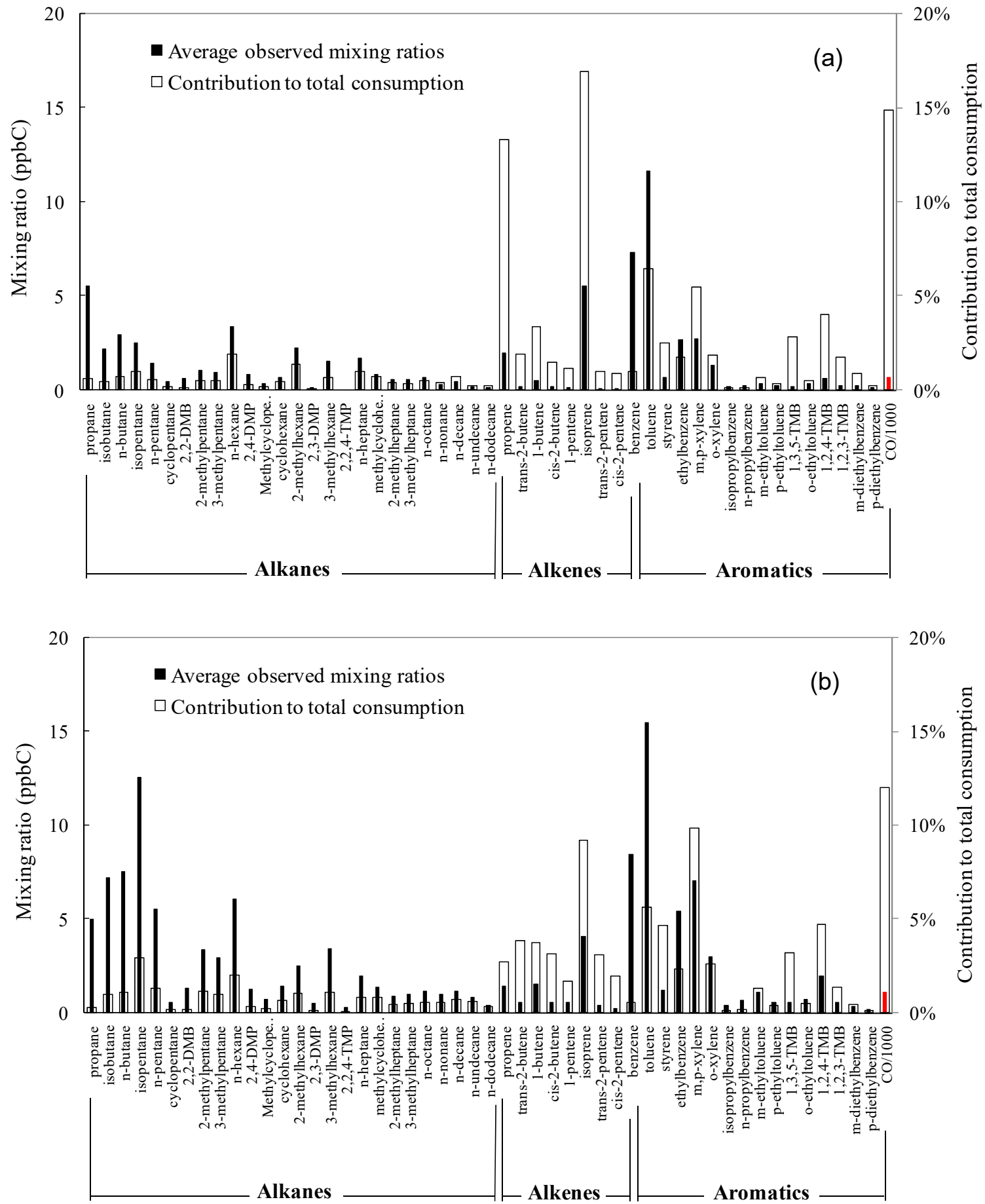

Figure 3. Average observed mixing ratios and contribution to total consumption of individual NMHCs and CO at (a) BG, PRD; (b) PKU, Beijing during the periods of the daily maximum oxidants (13:00 to 15:00 at BG and 12:00 to 14:00 at PKU). The red bar denotes the mixing ratio of CO/1000. (2,4-DMB: 2,2-dimethylbutane, 2,4-DMP: 2,4-dimethylpentane, 2,3-DMP: 2,3-dimethylpentane, 2,2,4-TMP: 2,2,4-trimethylpentane, 1,3,5-TMB: 1,3,5-trimethylbenzene, 1,2,4-TMB: 1,2,4-trimethylbenzene).

\section{Conclusions}

An OBM was developed to quantify the relationship between the consumption of precursors and the concentration of oxidants based on the aging indicator $\mathrm{E} / \mathrm{X}$. We propose a simple cause-effect hypothesis: the greater the amount of a precursor is consumed, the higher the oxidant level that can be produced. Large contributions to total consumption were seen at BG for isoprene (17\%) and propene 
$(13 \%)$ due to strong emissions from biogenic sources and the widespread use of LPG in vehicles, respectively. Alkenes and aromatics were more efficient in oxidant formation than alkanes at both BG ( 0.74 and 0.44 vs. 0.25 , respectively) and PKU ( 0.62 and 0.30 vs. 0.14 , respectively). The method introduced here provides an easy quantitative way to assess the consumption efficiency of individual NMHCs. To most efficiently reduce ozone in non-attainment areas and to strike a delicate balance between economic development and air quality, the calculation of consumption of precursors provides quantitative guidance to optimize abatement of precursors with high consumption potentials to achieve the most cost-effective results.

Author Contributions: Conceptualization, C.-C.C. and J.-L.W.; methodology, C.-C.C.; validation, H.-K.Y., C.-C.C.; formal analysis, C.-C.C.; investigation, C.-C.C.; resources, C.-C.C.; data curation, H.-K.Y.; writing-original draft preparation, C.-C.C.; writing—review and editing, J.-L.W.; visualization, H.-K.Y.; supervision, J.-L.W.; project administration, C.-C.C. All authors have read and agreed to the published version of the manuscript.

Acknowledgments: The authors would like to thank the PRIDE-PRD2006 and CAREBEIJING-2006 campaign teams (Yuanhang Zhang, Tong Zhu, Shaw-Chen Liu, Min Shao, Yutaka Kondo, Kazuyuki Kita, Charles C. K. Chou, etc.). Special thanks to Limin Zeng and Sihua Lu for their kind assistance and logistic support at the field sites.

Conflicts of Interest: The authors declare no conflict of interest.

\section{References}

1. Hao, J.; Wang, L. Improving urban air quality in China: Beijing case study. J. Air Waste Manag. Assoc. 2005, 55, 1298-1305. [CrossRef]

2. Wang, T.; Ding, A.J.; Gao, J.; Wu, W.S. Strong ozone production in urban plumes from Beijing, China. Geophys. Res. Lett. 2006, 33, L21806. [CrossRef]

3. Beijing Environmental Protection Bureau [BJEPB]. Beijing Communiqué on Environmental Quality, 1998-2006. Available online: http://www.bjee.org.cn (accessed on 21 March 2020).

4. Wang, T.; Xue, L.; Brimblecombe, P.; Lam, Y.F.; Li, L.; Zhang, L. Ozone pollution in China: A review of concentrations, meteorological influences, chemical precursors, and effects. Sci. Total Environ. 2017, 575, 1582-1596. [CrossRef]

5. Lu, X.; Hong, J.; Zhang, L.; Cooper, O.R.; Schultz, M.G.; Xu, X.; Wang, T.; Gao, M.; Zhao, Y.; Zhang, Y. Severe surface ozone pollution in China: A global perspective. Environ. Sci. Technol. Lett. 2018, 5, 487-494. [CrossRef]

6. Ding, A.J.; Wang, T.; Thouret, V.; Cammas, J.P.; Nedelec, P. Tropospheric ozone climatology over Beijing: Analysis of aircraft data from the MOZAIC program. Atmos. Chem. Phys. 2008, 8, 1-13. [CrossRef]

7. Wang, T.; Poon, C.N.; Kwok, Y.H.; Li, Y.S. Characterizing the temporal variability and emission patterns of pollutant plumes in the Pearl River Delta of China. Atmos. Environ. 2003, 37, 3539-3550. [CrossRef]

8. Ding, A.; Wang, T.; Zhao, M.; Wang, T.; Li, Z. Simulation of sea-land breezes and a discussion of their implications on the transport of air pollution during a multi-day ozone episode in the Pearl River Delta of China. Atmos. Environ. 2004, 38, 6737-6750. [CrossRef]

9. Seinfeld, J.; Pandis, S.N. Atmospheric Chemistry and Physics: From Air Pollution to Climate Change; A Wiley-Interscience Publication: New York, NY, USA, 1998.

10. Jacob, D.J. Introduction to Atmospheric Chemistry; Princeton University Press: Princeton, NJ, USA, 1999; 266p.

11. Jin, X.M.; Holloway, T. Spatial and temporal variability of ozone sensitivity over China observed from the Ozone Monitoring Instrument. J. Geophys. Res. Atmos. 2015, 120, 7229-7246. [CrossRef]

12. Chameides, W.L.; Fehsenfeld, F.; Rodgers, M.O.; Cardelino, C.A.; Martinnez, J.; Parrish, D.; Lonneman, W.; Lawson, D.R.; Rasmussen, R.A.; Zimmerman, P.; et al. Ozone precursor relationships in the ambient atmosphere. J. Geophys. Res. 1992, 97, 6037-6055. [CrossRef]

13. Cardelino, C.A.; Chameides, W.L. An observation-based model for analyzing ozone precursor relationship in the ambient atmosphere. J. Air Waste Manag. Assoc. 1995, 45, 161-180. [CrossRef] [PubMed]

14. Cardelino, C.A.; Chameides, W.L. The application of data from photochemical assessment monitoring stations to the observation-based model. Atmos. Environ. 2000, 34, 2325-2332. [CrossRef]

15. Harley, R.A.; Russell, A.G.; McRae, G.J.; Cass, G.R.; Seinfeld, J.H. Photochemical modeling of the Southern California Air Quality Study. Environ. Sci. Technol. 1993, 27, 378-388. [CrossRef] 
16. Jacobson, M.Z.; Lu, R.; Turco, R.P.; Toon, O.B. Development and application of a new air pollution modeling system-part I: Gas-phase simulations. Atmos. Environ. 1996, 30, 1939-1963. [CrossRef]

17. Sillman, S.; Logan, J.A.; Wofsy, S.C. The sensitivity of ozone to nitrogen oxides and hydrocarbons in regional ozone episodes. J. Geophys. Res. 1990, 95, 1837-1851. [CrossRef]

18. Trainer, M.; Parrish, D.D.; Buhr, M.P.; Norton, R.B.; Fehsenfeld, F.C.; Anlauf, K.G.; Bottenheim, J.W.; Tang, Y.Z.; Weibe, H.A.; Roberts, J.M.; et al. Correlation of ozone with $\mathrm{NO}_{\mathrm{y}}$ in photochemically aged air. J. Geophys. Res. 1993, 98, 2917-2925. [CrossRef]

19. Lou, S.; Holland, F.; Rohrer, F.; Lu, K.; Bohn, B.; Brauers, T.; Chang, C.C.; Fuchs, H.; Häseler, R.; Kita, K.; et al. Atmospheric $\mathrm{OH}$ reactivities in the Pearl River Delta-China in summer 2006: Measurement and model results. Atmos. Chem. Phys. 2010, 10, 11243-11260. [CrossRef]

20. Wang, J.L.; Wang, C.H.; Lai, C.H.; Chang, C.C.; Liu, Y.; Zhang, Y.; Liu, S.; Shao, M. Characterization of ozone precursors in the Pearl River Delta by time series observation of non-methane hydrocarbons. Atmos. Environ. 2008, 42, 6233-6246. [CrossRef]

21. Takegawa, N.; Miyakawa, T.; Kondo, Y.; Jimenez, J.L.; Worsnop, D.R.; Fukuda, M. Seasonal and diurnal variations of submicron organic aerosol in Tokyo observed using the Aerodyne Aerosol Mass Spectrometer. J. Geophys. Res. 2006, 111, D11206. [CrossRef]

22. Chou, C.C.-K.; Tsai, C.-Y.; Shiu, C.-J.; Liu, S.C.; Zhu, T. Measurement of NOy during Campaign of Air Quality Research in Beijing 2006 (CAREBeijing-2006): Implications for the ozone production efficiency of $\mathrm{NO}_{\mathrm{x}}$. J. Geophys. Res. 2009, 114, D00G01. [CrossRef]

23. Lee, B.S.; Wang, J.L. Concentration variation of isoprene and its implications for peak ozone concentration. Atmos. Environ. 2006, 40, 5486-5495. [CrossRef]

24. Shiu, C.J.; Liu, S.C.; Chang, C.C.; Chen, J.P.; Chou, C.C.K.; Lin, C.Y.; Young, C.Y. Photochemical production of ozone and control strategy for Southern Taiwan. Atmos. Environ. 2007, 41, 9324-9340. [CrossRef]

25. Monod, A.; Sive, B.C.; Avino, P.; Chen, T.; Blake, D.R.; Rowland, F.S. Monoaromatic compounds in ambient air of various cities: A focus on correlations between the xylenes and ethylbenzene. Atmos. Environ. 2001, 35, 135-149. [CrossRef]

26. Atkinson, R.; Arey, J. Atmospheric degradation of volatile organic compounds. Chem. Rev. 2003, 103, 4605-4638. [CrossRef]

27. Nelson, P.F.; Quigley, S.M. The m,p-xylenes: Ethylbenzene ratio. A technique for estimating hydrocarbon age in ambient atmospheres. Atmos. Environ. 1983, 17, 659-662. [CrossRef]

28. Rappenglück, B.; Fabian, P.; Kalabokas, P.; Viras, L.G.; Ziomas, I.C. Quasi-continuous measurements of non-methane hydrocarbons (NMHC) in the greater Athens area during MECAPHOT-TRACE. Atmos. Environ. 1998, 32, 2103-2121. [CrossRef]

29. Chang, C.C.; Wang, J.L.; Liu, S.C.; Lung, S.C. Assessment of vehicular and non-vehicular contributions to hydrocarbons using exclusive vehicular indicators. Atmos. Environ. 2006, 40, 6349-6361. [CrossRef]

30. Bowman, F.; Seinfeld, J. Ozone Productivity of Atmospheric Organics. J. Geophys. Res. 1994, 99, 5309-5324. [CrossRef]

31. Jeffries, H.E. Photochemical Air Pollution. In Composition, Chemistry, and Climate of the Atmosphere; Singh, H.B., Ed.; Van Nostrand Reinhold: New York, NY, USA, 1995; Section 9.4.1.

32. Reimann, S.; Pierluigi, C.; Hofer, P. The anthropogenic fraction contribution to isoprene concentrations in a rural atmosphere. Atmos. Environ. 2000, 34, 109-115. [CrossRef]

33. Borbon, A.; Fontaine, H.; Veillerot, M.; Locoge, N.; Galloo, J.C.; Guillermo, R. An investigation into the traffic-related fraction of isoprene at an urban location. Atmos. Environ. 2001, 35, 3749-3760. [CrossRef]

34. Guenther, A.; Zimmerman, P.; Harley, P.; Monson, R.; Fall, R. Isoprene and monoterpene emission rate variability: Model evaluation and sensitivity analysis. J. Geophys. Res. 1993, 98, 12609-12617. [CrossRef]

35. Rasmussen, R.A.; Khalil, M.A.K. Isoprene over the Amazon Basin. J. Geophys. Res. 1988, 93, 1417-1421. [CrossRef]

36. Liu, S.C. Possible effects on tropospheric $\mathrm{O} 3$ and $\mathrm{OH}$ due to $\mathrm{NO}$ emission. Geophys. Res. Lett. 1977, 4, 325-328. [CrossRef]

37. Levy, H., II; Mahlman, J.D.; Moxim, W.J.; Liu, S.C. Tropospheric ozone: The role of transport. J. Geophys. Res. 1985, 90, 3753-3772. [CrossRef]

38. Sillman, $\mathrm{S}$. The relation between ozone, $\mathrm{NO}_{\mathrm{x}}$, and hydrocarbons in urban and polluted rural environments. Atmos. Environ. 1999, 33, 1821-1845. [CrossRef] 
39. Kleinman, L.I.; Daum, P.H.; Lee, Y.-N.; Nunnermacker, L.J.; Springston, S.R.; Weinstein-Lloyd, J.; Rudolph, J. Ozone production efficiency in an urban area. J. Geophys. Res. 2002, 107, 4733. [CrossRef]

40. Xu, J.; Zhang, Y.H.; Fu, J.S.; Zheng, S.Q.; Wang, W. Process analysis of typical summertime ozone episodes over the Beijing area. Sci. Total Environ. 2008, 399, 147-157. [CrossRef]

41. Lai, C.H.; Chang, C.C.; Shao, M.; Zhang, Y.; Wang, J.L. Emissions of Liquefied Petroleum Gas (LPG) from Motor Vehicles. Atmos. Environ. 2009, 43, 1456-1463. [CrossRef]

42. Shao, M.; Lu, S.; Liu, Y.; Xie, X.; Chang, C.C.; Huang, S.; Chen, Z. Volatile organic compounds measured in summer in Beijing and their role in ground-level ozone formation. J. Geophys. Res. 2009, 114, D00G06. [CrossRef]

43. Atkinson, R. Atmospheric chemistry of VOCs and NOx. Atmos. Environ. 2000, 34, 2063-3101. [CrossRef]

(C) 2020 by the authors. Licensee MDPI, Basel, Switzerland. This article is an open access article distributed under the terms and conditions of the Creative Commons Attribution (CC BY) license (http://creativecommons.org/licenses/by/4.0/). 